\title{
Complex Electrical Stimulation Systems in Motor Function Rehabilitation after Spinal Cord Injury
}

\author{
Jiange Kou, ${ }^{1}$ Maolin Cai, ${ }^{1}$ Fei Xie $\mathbb{D},{ }^{2}$ Yixuan Wang $\mathbb{D},{ }^{1}$ Na Wang $\mathbb{D},{ }^{3}$ and Meng Xu ${ }^{4}$ \\ ${ }^{1}$ School of Automation Science and Electrical Engineering, Beihang University, Beijing 100191, China \\ ${ }^{2}$ Department of Pulmonary and Critical Care Medicine, Chinese PLA General Hospital, Beijing 100039, China \\ ${ }^{3}$ Engineering Training Center, Beihang University, Beijing 100191, China \\ ${ }^{4}$ Department of Orthopedics, Chinese PLA General Hospital, Beijing 100039, China \\ Correspondence should be addressed to Fei Xie; xiefei0522@163.com
}

Received 24 May 2021; Revised 16 July 2021; Accepted 30 September 2021; Published 25 October 2021

Academic Editor: Wen Qi

Copyright $\odot 2021$ Jiange Kou et al. This is an open access article distributed under the Creative Commons Attribution License, which permits unrestricted use, distribution, and reproduction in any medium, provided the original work is properly cited.

\begin{abstract}
Spinal cord injury (SCI) is an existing incurable disease that brings great pain and life obstacles to patients. Spinal cord electrical stimulation is an effective means to alleviate spinal cord injury. However, its complicated mechanism of action is still unclear. This article aims to summarize several different spinal cord electrical stimulation methods, analyze the stimulation effect, and briefly describe the current understanding of its origin and mechanism of action. In recent years, several application cases of the electrical stimulation system of stimulation methods have confirmed its positive effects in spinal cord injury diseases and provided new perspectives for the improvement of spinal cord injury. Finally, the possible development direction and corresponding challenges of spinal cord electrical stimulation in the future are proposed.
\end{abstract}

\section{Introduction}

1.1. Spinal Cord Injury. Spinal cord injury (SCI) is a transverse injury of the spinal cord caused by various pathogenic factors (trauma, tumor, inflammation, etc.). The spinal cord is part of the central nervous system and consists of a large bundle of nerves that allow the brain to communicate with the rest of the body (through the peripheral nerves). Once SCI occurs, it will lead to spinal cord nerve dysfunction below the injury level, such as sensory and autonomic dysfunction, impaired motor function, and sphincter and autonomic nerve dysfunction [1]. This brings great life pressure and psychological burden to patients and their families. Traumatic SCI has the characteristics of acute onset, serious condition, high disability-fatality rate, and so on. The treatment of traumatic SCI is also a worldwide problem [2-4], and the incidence of $\mathrm{SCI}$ is increasing year by year [5]. The high incidence of SCI is mostly caused by traffic accidents, falls, violence, and other factors [6]. After SCI, how to restore nerve function to enable paraplegic patients to obtain motor ability is still a difficult problem in life science.
There are surgical treatment [7], drug therapy [8], physical rehabilitation [9], and other treatment methods for patients with SCI. Surgical treatment is generally concentrated in the acute stage of spinal cord injury, but the influence of the timing of surgical decompression is still discussed, and there are a large number of changes in clinical practice [10]. Drug therapy generally plays a role in reducing inflammation but does not play a significant role in the improvement of motor function [8]. As a common treatment, physical rehabilitation has been used in patients with spinal cord injury and achieved certain results. However, the individual specificity of physical rehabilitation treatment is strong, and the universality needs to be improved [9]. In addition, there are new treatments such as biomaterials or stem cell transplantation $[11,12]$. But the pathophysiological mechanism of spinal cord injury is complex, changeable, and multi-inducing, and the mechanisms are still unclear [13], which brings great obstacles to the treatment of spinal cord injury.

So far, great efforts have been made to solve this problem in various fields around the world. SCI is no longer a single 
medical problem, but a life science difficulty to be overcome in biomedical, mechanical and electronic, computer, information, and other fields. Engineering methods that combine multiple fields are used to treat spinal cord injuries, such as electrical stimulation techniques.

\subsection{Electrical Stimulation Technique. Electric current can} cause responses in excitable cells, including neurons, and can be used to produce sensory or motor feedback. Through this principle, the researchers invented the electrical stimulation technology and carried out the initial clinical application. The spinal cord has become an attractive stimulation target, because it retains motor and sensory pathways below the injury level $[14,15]$. The existing methods of spinal cord electrical stimulation include epidural electrical stimulation, transcutaneous stimulation, and intraspinal electrical stimulation. Its effectiveness can be verified by several examples, including hand grip [16], walking $[17,18]$, protecting spinal motor neurons [19], and bladder management [20].

Most of the early electrical stimulation techniques set the stimulation parameters through the stimulation system and did not form a complete closed-loop control. However, with the development of science and technology, such as braincomputer interface technology, electrical stimulation technology is gradually improved. As shown in Figure 1, Depending on the recording method, neuroscientists distinguish between electroencephalogram (EEG), electrocorticogram (ECoG), and local field potential (LFP). Highfrequency collection of single nerve cell discharges peak potential spike [21]. Researchers can collect EEG as control signals to extract the characteristic information contained in the signals. By means of machine learning, the feature information is classified, and the mapping relationship between the feature information and the action is established and transformed into stimulus signals. After that, when this type of signal is collected again, the receptor can be stimulated to produce the corresponding action, and finally the motor function can be restored. This technique has also been applied to solve the problem of SCI, and a breakthrough has been achieved [22]. The purpose of this paper is to summarize the different methods of spinal cord electrical stimulation used to restore motor function, analyze their advantages and disadvantages, and briefly introduce the potential future of this technique.

\section{Key Components of Electrical Stimulation System}

2.1. Electrical Stimulator. The electrical stimulator is used to generate different stimulating currents, which are connected to the electrode to achieve the purpose of transmitting the current. In general, electrical stimulators can connect one or more channels, each consisting of a pair of electrodes (anode and cathode), and each channel is independent of each other. The electrical stimulator can set different pulse parameters (amplitude, pulse width) and the stimulation sequence of each channel, resulting in different stimulation strategies.
2.2. Electrodes. The electrode is used to make direct contact with the stimulated target to transmit electric current. According to its placement position, it can be divided into the implantable electrode and nonimplantable electrode. Implantable electrodes are generally flaky (mostly epidural electrical stimulation) or needle (mostly intraspinal electrical stimulation), which need to be surgically implanted in the body. It can be closer to the stimulus position but also requires a smaller stimulus current, which is generally less than $25 \mathrm{~mA}$. Nonimplantable electrodes are generally attached to the skin above the spinal cord, do not require surgical participation, are very suitable for temporary use, and can adjust the stimulation position to produce the desired effect (movement). Because the electrode and the stimulation position are separated from the skin, it generally requires a large current and will be controlled within the $120 \mathrm{~mA}$, as shown in Table 1 .

In addition to the electrode position and current, the key factors affecting the effect of electrical stimulation are frequency, pulse width, and so on. The stimulation frequency is the rate of pulse transmission, which affects the speed of muscle contraction. Exceeding $40 \mathrm{~Hz}$ will cause tetanic contraction of muscles, and spinal cord electrical stimulation is generally used at $20-25 \mathrm{~Hz}$. Current amplitude and pulse width will affect the stimulation effect at the same time, and there is an inverse correlation between them, and they work together to produce enough energy to produce a response. In order to achieve the comfort of stimulating effect, the current amplitude is generally controlled within $100 \mathrm{~mA}$ [23].

2.3. Sensors. There may be sensors as auxiliary devices to obtain better stimulation effects for different stimulation strategies. For example, stimulus strategies based on inertial sensors are more smoothly controlled [24], trigger algorithm based on inertial sensor to assist paraplegic patients to swim [25], using EMG signal electrical stimulation feedback control [26], and so on. The prediction of motor behavior based on sensor information [27, 28] and physical rehabilitation training can help patients return to normal life to the greatest extent.

2.4. Control Systems. It is difficult to control the pulse frequency, amplitude, pulse width, and other stimulation parameters for the electrical stimulation system. It is also the most important part of the stimulation system. While producing a stimulating effect, ensure the safety, comfort, and individual differences of the system. These parameters will affect the stimulation effect and ultimately affect the patient's rehabilitation progress. Appropriate stimulation parameters will improve the efficiency of stimulation, and unreasonable parameters are likely to hinder the patient's recovery.

The research on electrical stimulation control system focuses on (1) open-loop and closed-loop control, (2) control algorithm technology research, or (3) feedback information to the stimulator control unit through biological signals or sensors $[29,30]$. The control objects are mainly 


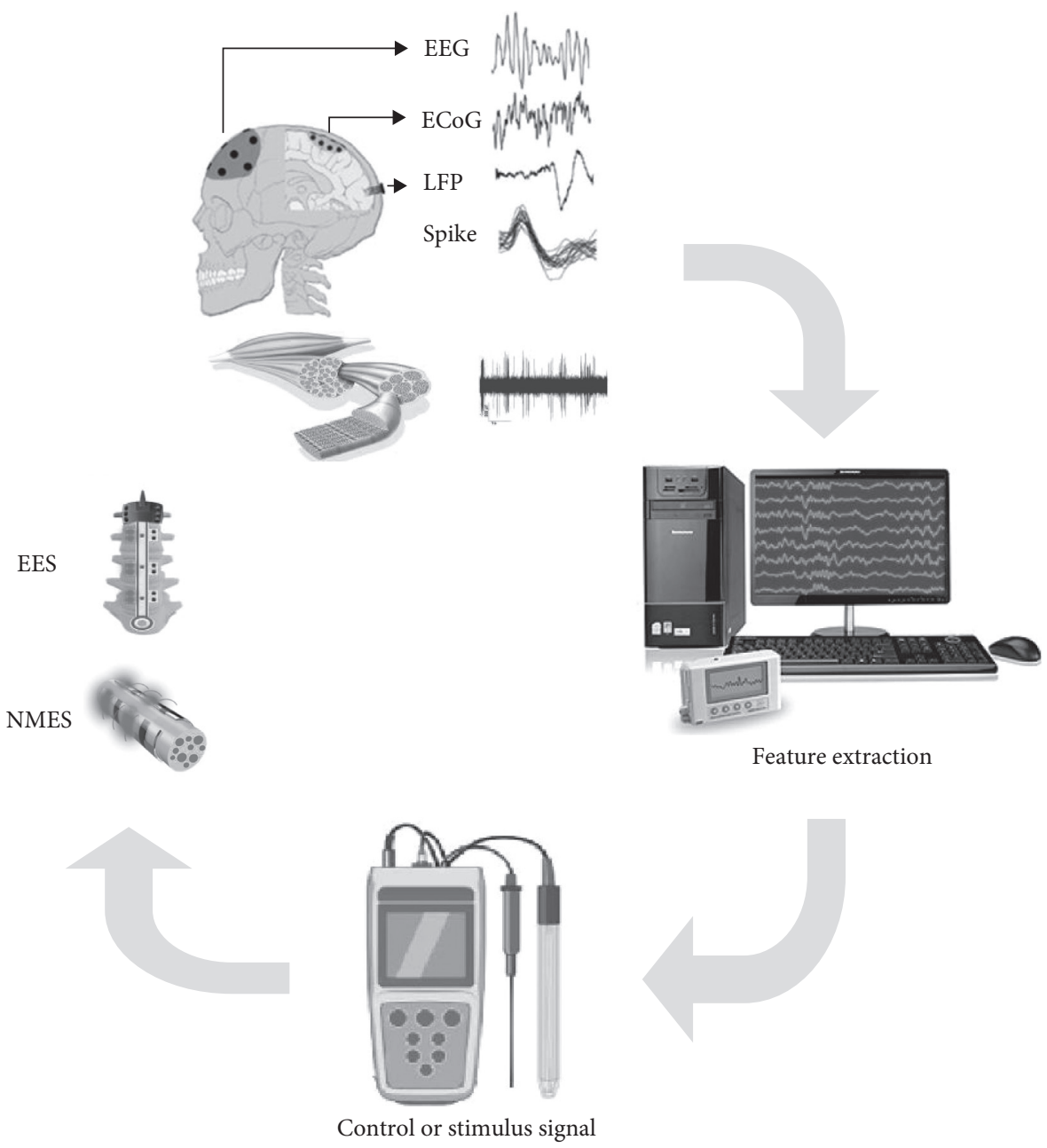

FIGURE 1: Electrical stimulation technology based on brain-computer interface.

TABLe 1: Different stimulation electrodes are compared.

\begin{tabular}{lccc}
\hline Electrode & Current $(\mathrm{mA})$ & Advantage & Disadvantage \\
\hline $\begin{array}{l}\text { Implantable electrode } \\
\begin{array}{l}\text { Nonimplantable } \\
\text { electrodes }\end{array}\end{array}$ & $<25$ & High specificity, can be used for a long time & Need surgery, may have inflammation \\
\hline
\end{tabular}

focused on stimulation frequency, stimulation amplitude, etc. [15]. Researchers have verified through experiments that closed-loop control may be more practical [31-33], as shown in Figure 2.

\section{Types of Spinal Stimulation}

Spinal cord electrical stimulation technology first appeared in the treatment of clinical cases in the 1970s. Initially, this technology was used to delay muscle atrophy and anti-inflammatory symptoms caused by muscle waste in patients with hemiplegia. It can also promote the speed of physical recovery [34-36]. Spinal cord electrical stimulation is a relatively new application for the recovery of motor function. Researchers use this technique to treat paraplegia, paralysis, or functional disorders caused by SCI or stroke [37-39].
Researchers have identified several effective forms of electrical stimulation, which can be divided into (1) epidural electrical stimulation, which places electrodes on the dural surface of the spinal cord, (2) transcutaneous electrical stimulation, where the electrode was placed on the skin above the vertebra, and (3) intraspinal electric stimulation, where the electrode was inserted into the spinal cord, as shown in Figure 3. Different stimulation methods require different stimulation parameters, and their mechanism of action will be different [40]. The current view is that epidural and transcutaneous electrical stimulation mainly stimulate the baseline excitability of the spinal cord and reactivate the intact circuit retained after SCI [41]. By activating the motor cistern and the neural network in the spinal cord, the electrical stimulation in the spinal cord can obtain the coordinated movement of the whole limb [42]. 


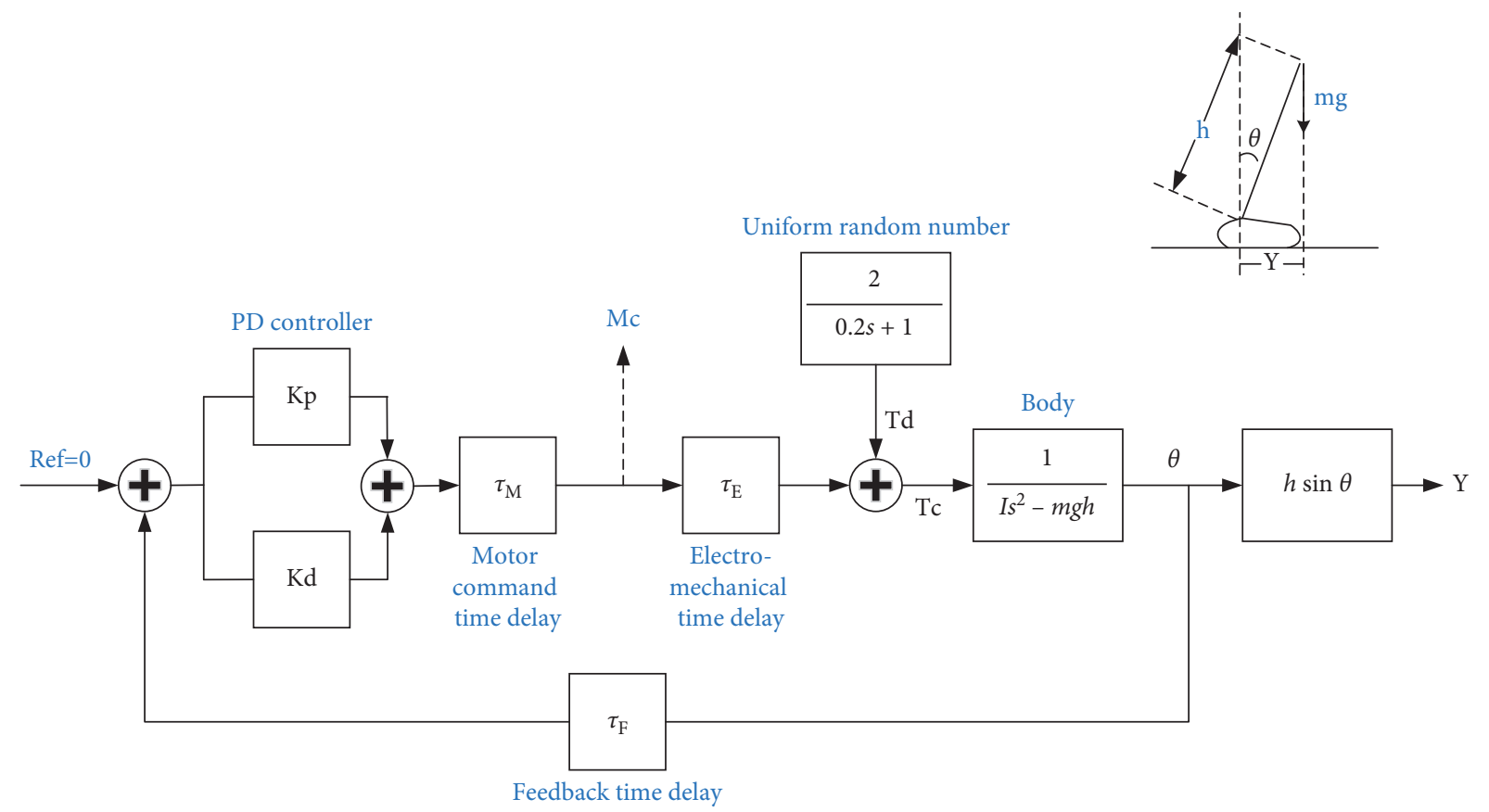

Figure 2: Inverted pendulum model and static attitude closed-loop control scheme. $Y$ is the horizontal center of gravity (COM) position, $h$ is the distance from COM to the ankle joint, $\theta$ is the body swing angle, $g$ is the acceleration caused by gravity, $M c$ is the nerve movement command of the plantar flexor, and $T c$ is the total torque of the ankle joint [31]. In order to maintain a safe standing, an effective and safe control stimulation method is necessary.

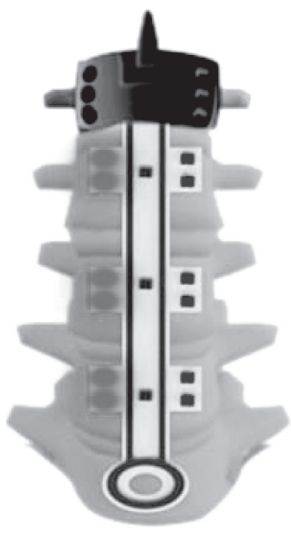

(a)

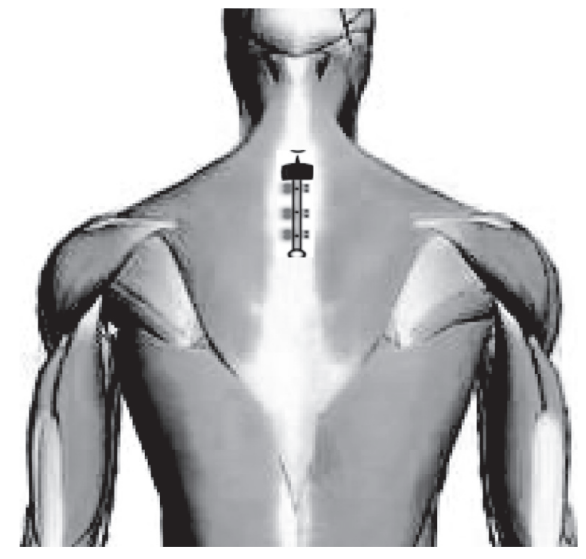

(b)

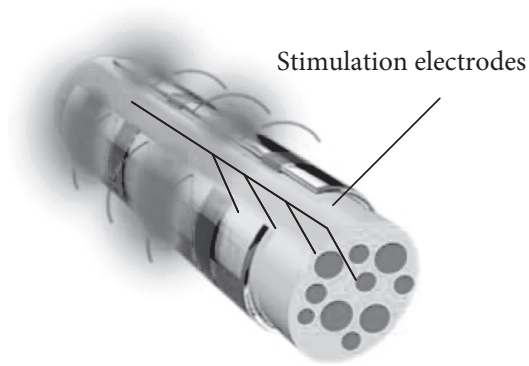

(c)

FIgURE 3: Types of spinal stimulation. (a) Epidural electrical stimulation; (b) transcutaneous electrical stimulation; (c) intraspinal electric stimulation.

3.1. Epidural Electrical Stimulation. The electrode is placed in the spinal cord epidural, through different current parameters to stimulate the electrode contact position, so as to achieve the effect of treatment or adjuvant therapy, and this technique is called epidural electrical stimulation. In the study of spinal cord function and its ecological environment, it is found that the functional modules of spinal cord can produce complex motor behavior without brain input $[43,44]$. In fact, most of our daily actions escape our conscious attention. It also shows that it is possible to directly stimulate the downstream of the SCI plane beyond the SCI plane to cause the target movement of the moving organs.
The researchers applied epidural electrical stimulation to several animal models of SCI to verify the effectiveness of this technique [45-48]. It is undoubtedly a good choice to use small rodent models to verify this point of view. Gad et al. pointed out that, after complete resection of the middle thoracic spinal cord, adult rats can use spinal cord epidural stimulation to step on an electrically driven treadmill. At the same time, the effect of the combination of subthreshold stimulation intensity and spontaneous load proprioception to promote the walking and standing of hind limbs in paralyzed rats was studied [49]. Alam et al. used epidural electrical stimulation with different stimulation parameters (including different stimulation frequencies and single and 
double stimulation electrodes) to train the forelimb grasping ability of rats with SCI. They found that cervical epidural stimulation increased the grip success rate compared with the nonstimulation condition, and bipolar stimulation (C6$\mathrm{C} 8+$ and $\mathrm{C} 6+\mathrm{C} 8-)$ produced a larger spinal motor evoked potential and led to a higher success rate of arrival and mastery [50]. Studies in rats have found that epidural electrical stimulation of the lumbar spinal cord can reproduce the natural activation of synergistic muscle groups that produce motor function. Creating a suitable calculation model may be able to break through the complex mechanism of electrical stimulation. Capogrosso et al. designed a computational model and conducted in vivo experiments to study the types of fibers, neurons, and circuits that respond to EES recruitment. As shown in Figure 4, the model can predict the motor response induced by EES of various intensities and positions and provides a mechanical framework for the design of spinal nerve prosthesis system to improve standing and walking after nervous system diseases [51].

There is a certain gap between the anatomical structure of rodents and human beings. For rodents, spinal epidural electrical stimulation has achieved a good stimulation effect. However, in human testing, sometimes it does not work as well as in rodents. Studies have shown that EES cannot block proprioceptive input in rats but can block a large number of proprioceptive inputs in human body, which may be caused by different lengths of neural circuits [52], as shown in Figure 5. The results of Friedli et al. reveal that the fundamental differences in the essential anatomical and functional characteristics of the motor system between primates and rodents may lead to significant interspecific differences in the nature and degree of spinal cord repair mechanisms. It is suggested that although rodents are still very important in promoting regenerative therapy, the unique response of the corticospinal tract of primates after injury once again emphasizes the importance of primate models [53].

Some research teams set out to improve the electrical stimulation of primate models. Capogrosso et al. implanted a wirelessly controlled spinal cord stimulation system in rhesus monkeys with unilateral corticospinal tract lesions, which linked the online neural decoding of leg stretching and flexion movements to stimulation protocols that promote these movements. Without prior training for monkeys, the brain-spine interface restores the load-bearing movement of paralyzed legs on the treadmill and on the ground [54]. They made an in-depth study of the stimulation mechanism of the cervical spinal cord, showing that the lateral electrodes produce segmented recruitment of motoneurons in the upper limb and regulate the muscle response during exercise [55]. In order to explore the location of stimulation, Mesbah et al. carried out the research by means of statistics, discussed the mechanism of motor function recovery, and finally determined the exact position of the electrode [56]. Barra et al. recorded the muscle activity of rhesus monkeys during the hand-holding task and found that the task involved a stereotyped spatiotemporal map of motor neuron activation and characterized the specificity of EES delivery to the cervical vertebra segment. Finally, the team designed a stimulation scheme based on these results to reproduce the natural activation of motor neurons, thereby promoting the movement of the upper limb after injury [57]. This result also confirms the importance of spatiotemporal stimulation strategies for epidural electrical stimulation.

After exploration, epidural electrical stimulation can be systematically applied to human beings with SCI. As shown in Figure 6, patients with SCI are programmed into regular stimulation codes and sent to implantable pulse generators by collecting brain motor intention signals. The pulse generator connects a lamellar stimulation electrode attached to the dura matter of the L1 S2 segment of the spinal cord. By sending regular stimulation signals to the distributed contacts of the electrode, the lower limbs can be stimulated to make regular swinging movements.

In addition, there have been a number of cases to prove that spinal epidural stimulation has the effect of motor function recovery [59-63]. In 2011, Harkema et al. confirmed that a patient who has a complete motor injury but felt incomplete injury regained motor control after 2 years of complete paralysis by lumbosacral spinal cord epidural stimulation [64]. The David study showed that, 5 and 10 years after SCI, two adult women (48 years old and 52 years old, respectively) resumed a certain degree of voluntary exercise immediately after the implantation of the epidural spinal cord stimulation system, and there was no prescribed or obvious preconditioning training after the implantation of the stimulation system [65]. Possover stimulated the lumbosacral nerve in patients with chronic spinal cord injury for a long time. In the experiment, all patients with incomplete spinal cord injury regained voluntary control of previously paralyzed muscles [66]. The selection of appropriate stimulation strategy is very important to promote the standing of whole body weight-bearing stand with independent knee extension [67].

The Wagner team used an implantable pulse generator with real-time triggering to provide a series of spatially selective stimuli to the spinal cord in a certain time sequence. Within a week, this stimulation reestablished adaptive control of paralyzed muscles during ground walking. The exercise ability was improved during the rehabilitation period. A few months later, the participants regained voluntary control of previously paralyzed muscles without stimulation [58]. It is also shown that this kind of stimulation can produce long-term therapeutic effect.

Different stimulation parameters can produce different stimulation effects, and the influencing factors are complex and changeable, which brings difficulty to the control. Wenger et al. [46] developed a mechanical framework to optimize neural regulation in real time to achieve leg height simulation control during electrical stimulation. As shown in Figure 7, a parallel loop with a combination of robust feedback correction (PI controller) and predictive feedforward model is integrated by establishing a technical platform of embedded control strategy. The step height $\left(h_{i}\right)$ is collected as the input, and the linear relationship between the EES frequency and the step height is refined and iterated. The controller combines the error $\left(e_{i}\right)$ and the predicted value based on the current reference $\left(r_{i}\right)$ to adjust the current 


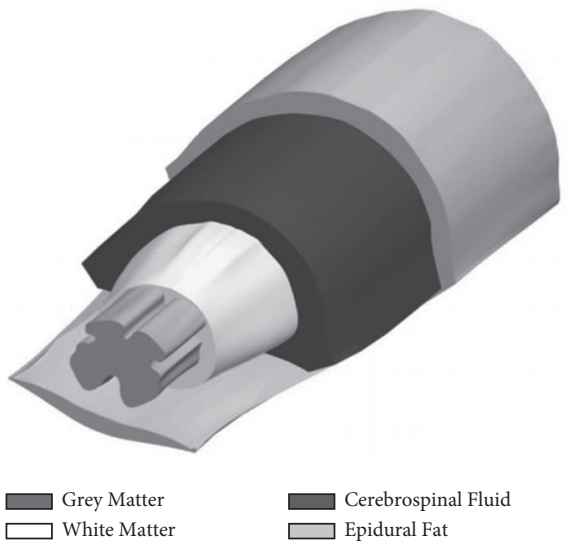

(a)

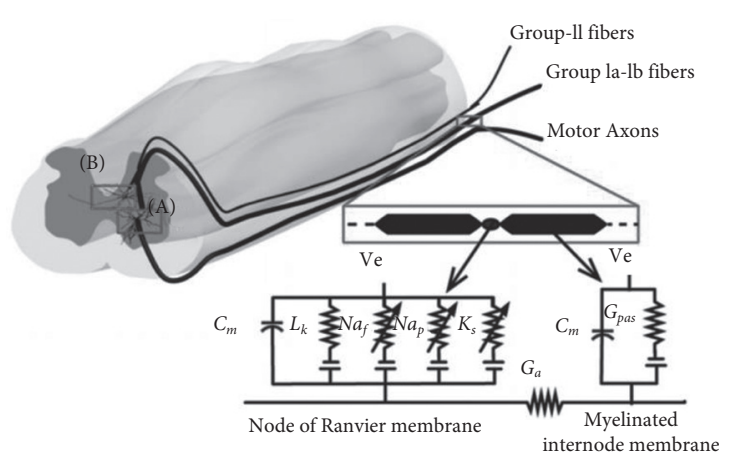

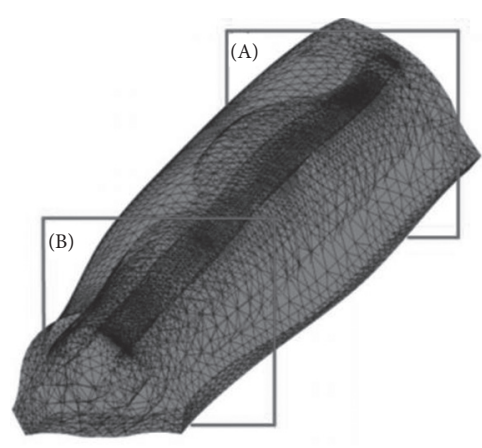
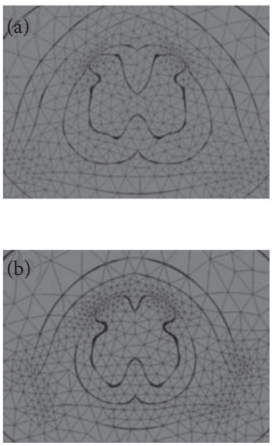

(b)

(A)

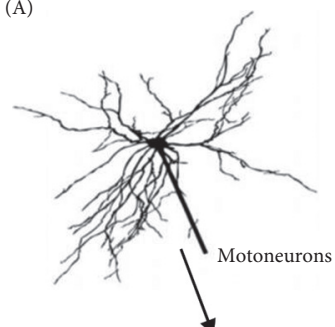

(B)

(c)

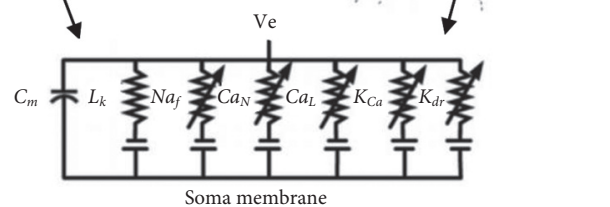

FIGURE 4: Characteristics of the computational model [51]. (a) Anatomically real spinal cord model, with different colors for gray matter and white matter, cerebrospinal fluid, and epidural fat. (b) The finite element structure of the spinal cord and the meshing of tetrahedral elements, as well as the cross-sectional schematic diagrams of the spine segments L2 (A) and S1 (B). (c) Modeling of afferent and efferent nerves, and establishing real geometric models of afferent and efferent fibers, $\alpha$ motor neurons and interneurons. The membrane potential was calculated by the Hodgkin-Huxley equation. The afferent fiber enters the spinal cord below the spine segment S1 and travels longitudinally before bending in the gray matter of its target segment. Interneurons are located in layers I to III and VII, and the efferent axons expand to the dorsal side or pass through the midline of the spinal cord, respectively.

frequency $\left(f_{i}\right)$ to the stimulus frequency $\left(f_{r+1}\right)$ in real time, so as to keep the step height within the set range of parameters.

\subsection{Transcutaneous Stimulation. Transcutaneous stimula-} tion refers to an electrode placed on the skin above the spinal cord, which penetrates the skin to the spinal cord to produce movement or grip [68]. To some extent, spinal transcutaneous stimulation increased the recovery of motor function in patients with SCI similar to epidural stimulation $[69,70]$.

Studies have shown that surface spinal stimulation, similar to epidural stimulation, can be used to enhance muscle recruitment without adversely affecting residual motion control in incomplete SCI [71]. The researchers performed percutaneous electrical stimulation of the spine in 15 SCI patients of different severity to restore their independent posture and found high levels of leg muscle activity during the standing weight shift achieved by spinal stimulation, depending on the muscle load. This suggests that transcutaneous stimulation can be used to regulate the lumbar spinal cord neural network to promote self-standing after chronic movement and complete paralysis [72]. Spinal cord stimulation and drugs can enhance the motor state of the subjects when they step into the exoskeleton. In addition, stimulation improved the coordination pattern of lower limb muscles, resulting in more continuous, smooth stepping movement of the exoskeleton [73]. This method can rejoin and train the spinal cord motor network of individuals with long-term complete motor paralysis. In some special cases, command selective activation of gastrocnemius and soleus was also observed [74].

The latest study has found that the use of painless transcutaneous electrical stimulation strategy to regulate the physiological state of the spinal cord can promote stampede in noninjured objects whose legs are in a gravity-neutral position, and multipoint stimulation can more effectively induce stepping movement [31]. Compared with the stampede driven by the robot alone, $30 \mathrm{~Hz}$ percutaneous spinal cord stimulation can increase the number of rhythmic 


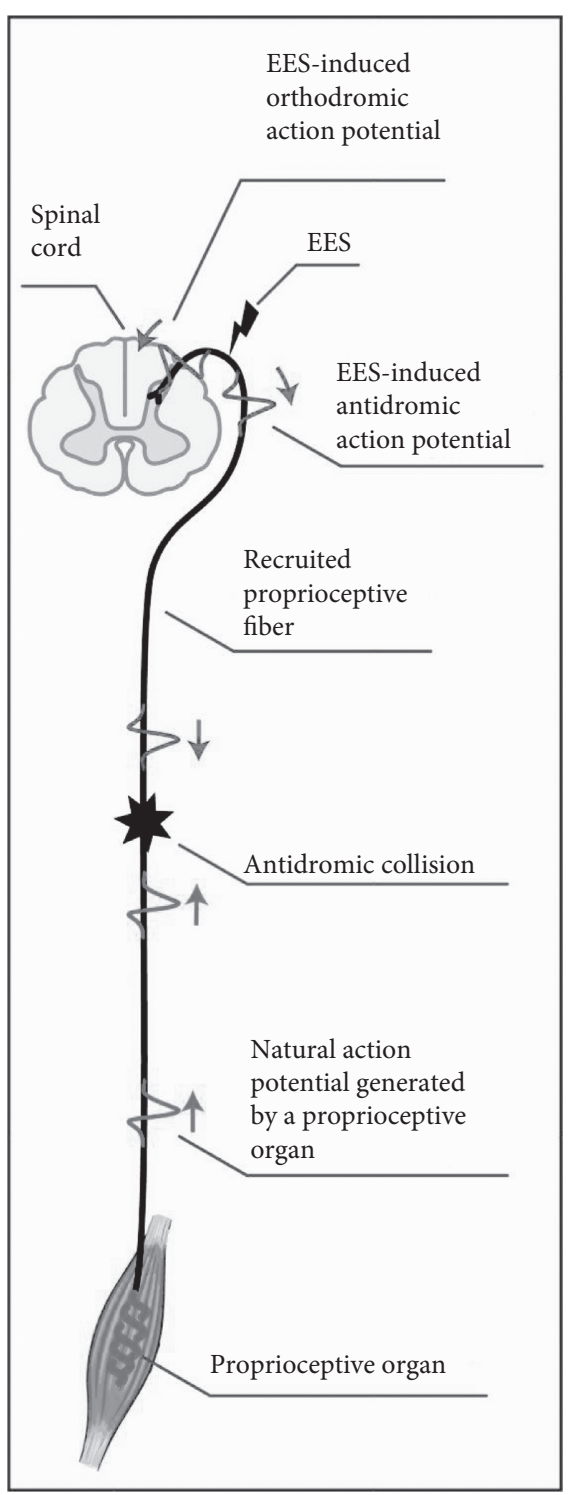

(a)

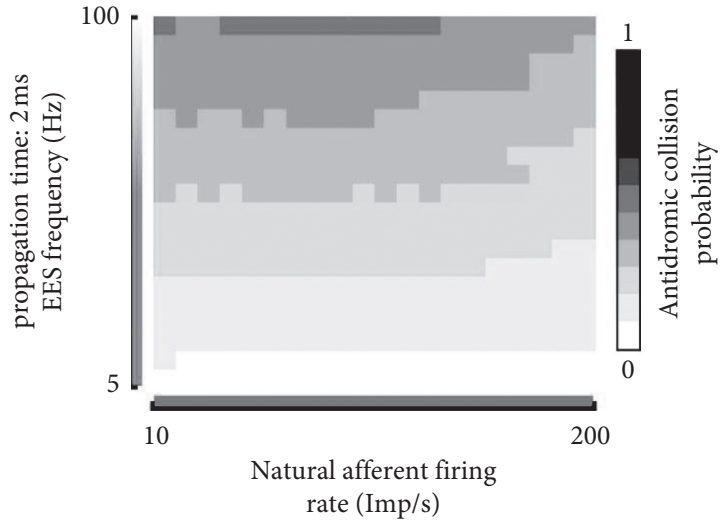

(b)

FIgURE 5: Continued. 

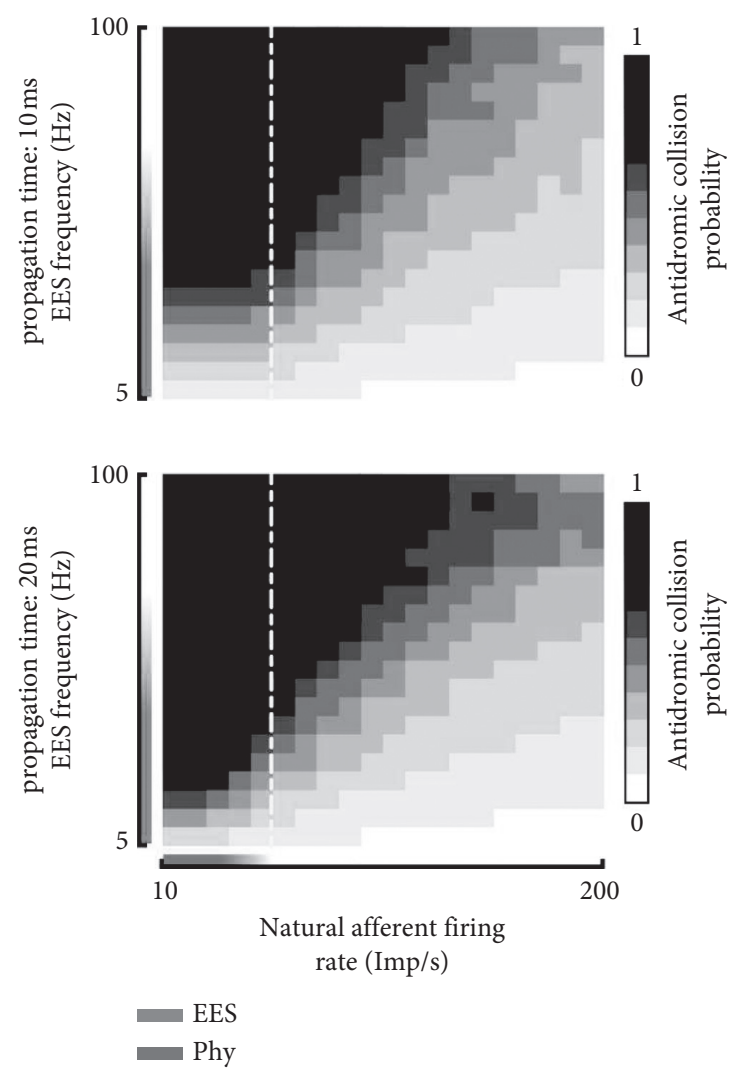

(c)

Figure 5: Probability of antidromic collisions during EES in rats and humans [52]. (a) Schematic diagram of the conflict between EESinduced action potentials and naturally occurring action potential; (b) the probability of action potential conflict in mice (the transmission time of action potential in mice is about $2 \mathrm{~ms}$ ); (c) the probability of action potential conflict in human body (the propagation time of action potential is about $10 \mathrm{~ms}$ in the proximal muscle circuit and about $20 \mathrm{~ms}$ in the distal muscle circuit).

muscles, enhance the activity of thigh muscles, and inhibit cloning. This shows that the rhythmic movement pattern produced by forced stampede is the response of spinal reflex circuit to cyclic sensory feedback. Providing additional stimulation and participation in spinal rhythm generation networks, combined with treadmill training, may increase rehabilitation outcome after severe SCI [75]. Similar to epidural electrical stimulation, transcutaneous stimulation also requires intensive treatment and physical exercise in the process of spinal cord stimulation to maximize motor function recovery [73]. After a long period of training, the noninvasive percutaneous electrical stimulation of the spinal network restores the movement and function of the hands and arms. This method of stimulation may be more suitable for patients with complete paralysis and long-term spinal cord injury. In addition, muscle spasm was reduced compared with invasive electrical stimulation, and the therapeutic effects of all six participants demonstrated long-term neuroplastic-mediated functional recovery [76].

Transcutaneous stimulation is a noninvasive stimulation that does not require surgery, so it is of sufficient interest to many people. However, percutaneous muscle stimulation has several practical limitations. Specifically, the skin has higher resistance than nerve tissue [77]. Therefore, most of them need higher current stimulation $(>30 \mathrm{~mA})$ to have an effect [78]. Sometimes, there is pain because of the location and individual differences of the electrodes [79]. Electrode placement and current intensity seem to be the key parameters to achieve selective response [80].

3.3. Intraspinal Electric Stimulation. The electrical stimulation in the spinal cord is different from the epidural electrical stimulation in that the electrode is implanted into the spinal cord, and the nerve region in the spinal cord is directly stimulated by the electrode power supply, because direct stimulation of the spinal cord requires a lower threshold current to induce movement than epidural stimulation, as shown in Table 2 [81].

So far, there are few studies on spinal cord electrical stimulation in humans, but the spinal cord stimulation experiments in animals provide a good research basis. Holinski used fine penetrating electrodes to stimulate the enlarged ventral horn of the waist of 5 adult anesthetized cats. The stimulation current of $<100 \mu \mathrm{A}$ activates the inherent motor network in the spinal cord, which can produce functional ground walking with bilateral coordination. This suggests that ISES may be an effective intervention for functional walking after SCI [82], as shown in Figure 8. 

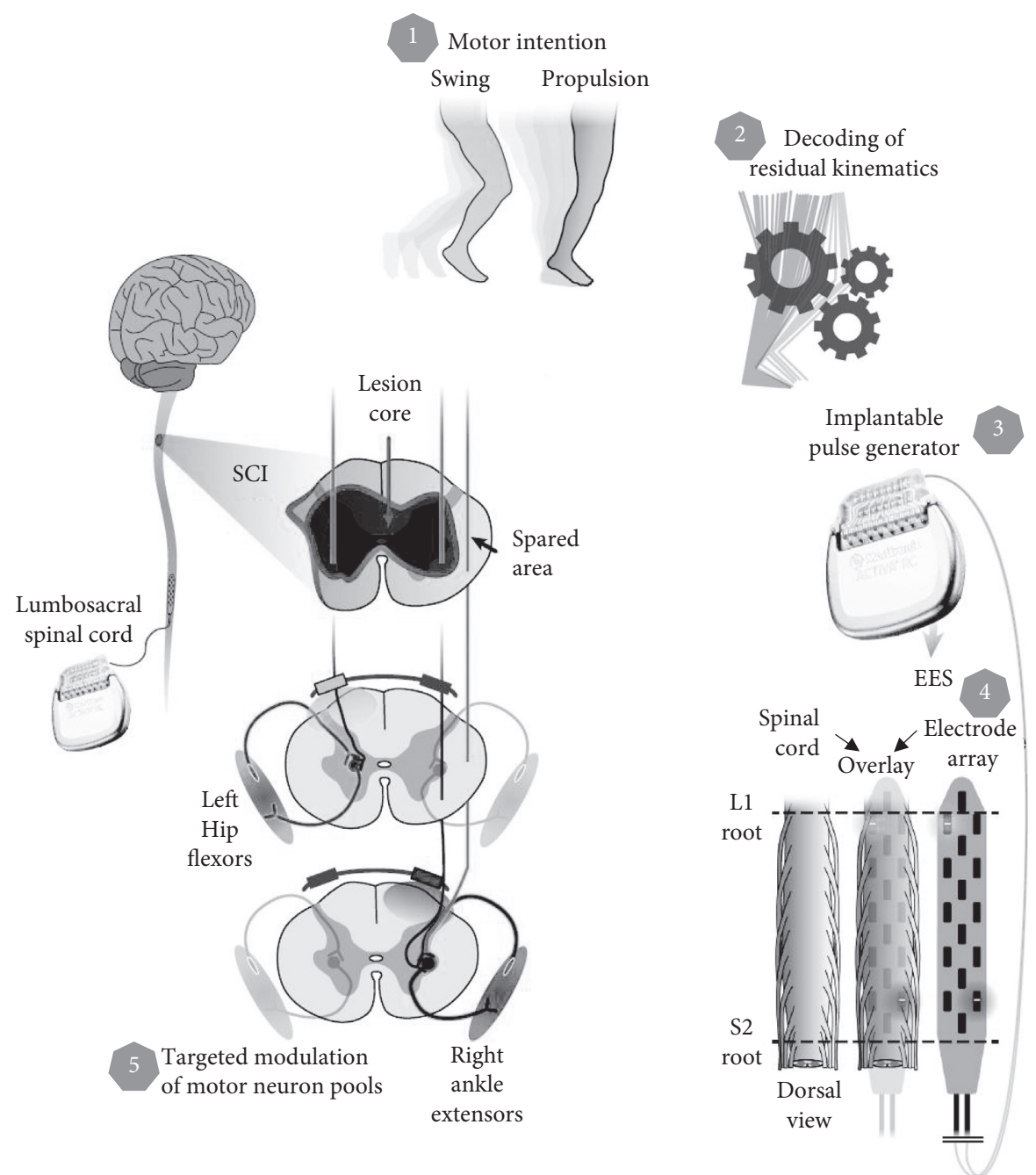

FIgURE 6: Schematic diagram of the structure of epidural electrical stimulation [58].

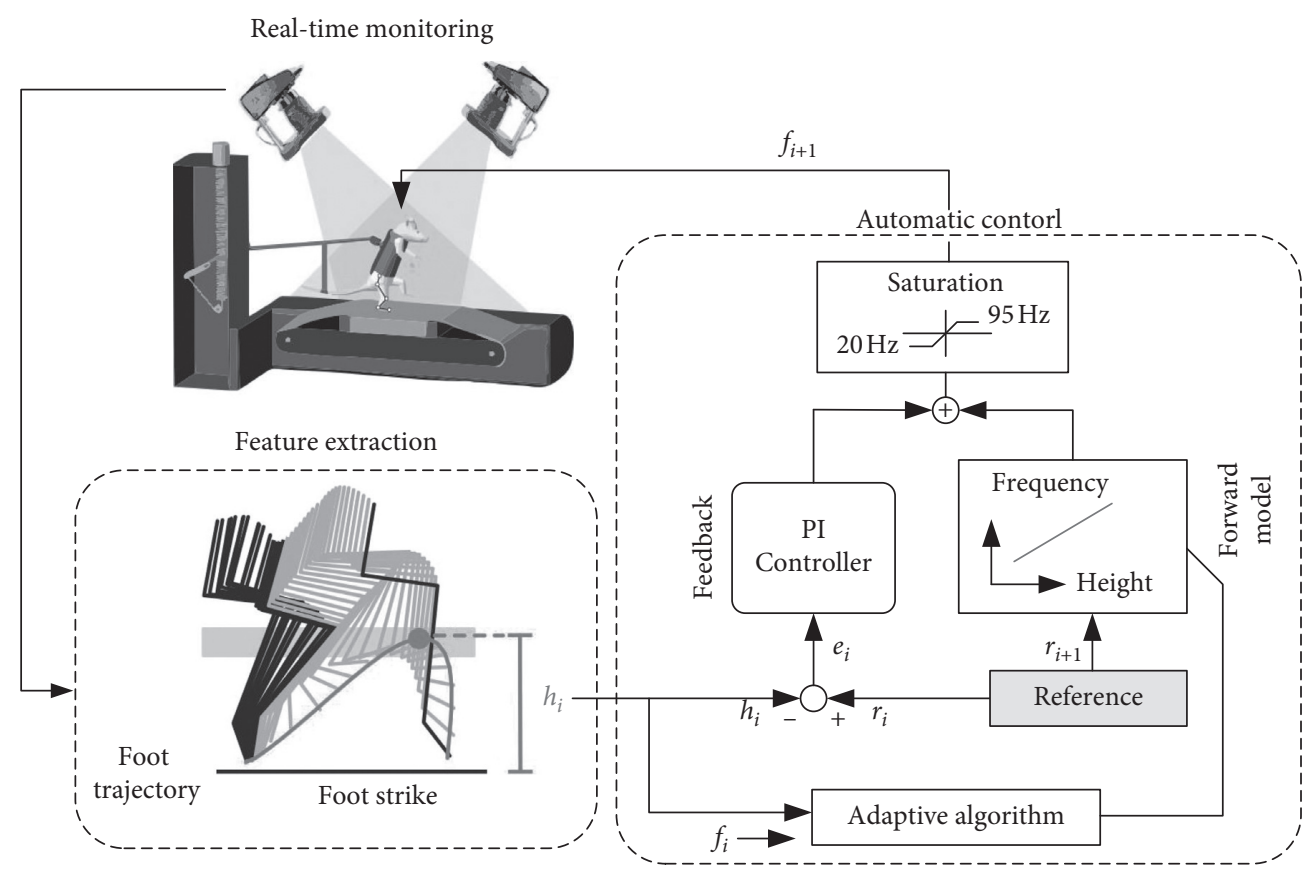

FigURE 7: Rat real-time feedback control platform [46]. 
TABLE 2: Comparison of stimulation current threshold of different stimulation modes of spinal cord [81].

\begin{tabular}{|c|c|c|c|}
\hline \multirow{2}{*}{ Motion type } & \multicolumn{2}{|c|}{ Threshold current $(\mu \mathrm{A})$} & \multirow{2}{*}{ Spine segment } \\
\hline & Epidural electrical stimulation (EES) & Intraspinal electric stimulation (ISES) & \\
\hline Hip flexion & $250 \sim 320$ & $88 \sim 110$ & T13 \\
\hline Hip extension & $180 \sim 282$ & $65 \sim 90$ & $\mathrm{~L} 2$ \\
\hline Hip adduction & $210 \sim 260$ & $82 \sim 103$ & $\mathrm{~L} 1$ \\
\hline Hip abduction & $230 \sim 278$ & $80 \sim 90$ & $\begin{array}{l}\text { T13 } \\
\text { L1 }\end{array}$ \\
\hline
\end{tabular}

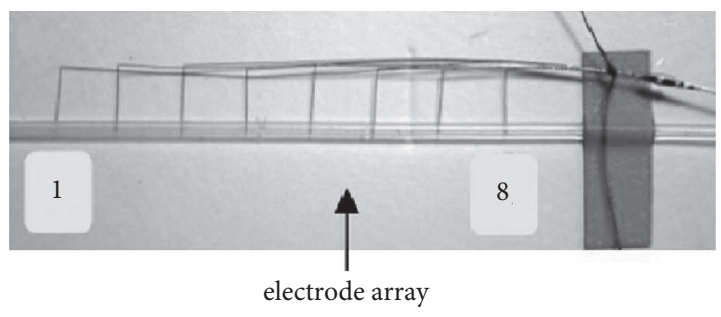

(a)

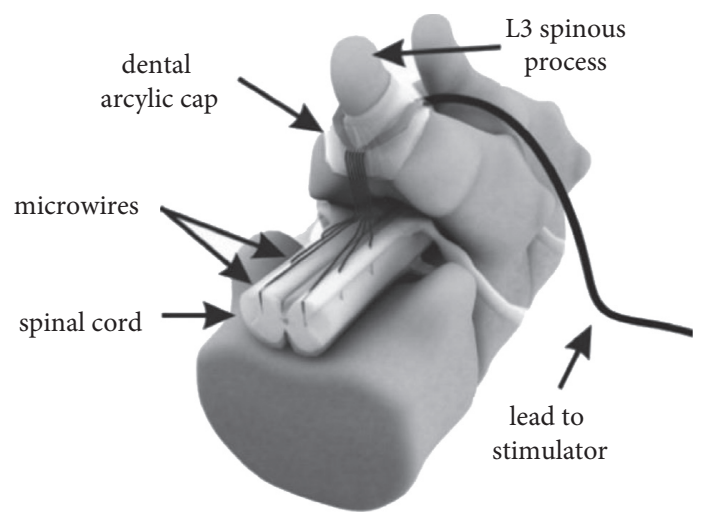

(b)

FIGURE 8: Electrode and implant location [82].

Dalrymple used electrical stimulation in the spinal cord and developed control strategies to achieve a cat model of hemisection SCI for weight-bearing pedaling [83]. In addition, in a number of rodent experimental studies, intraspinal cord stimulation is used after specific exercise [84, 85]. There will be a lasting improvement in forelimb movement a few weeks after the stimulation stops $[85,86]$. These results suggest the potential long-term effect of intraspinal stimulation. Pairing intraspinal cord stimulation with rehabilitation physical training may have additional benefits, and a specific study of the joint approach will be useful.

Different spinal cord stimulation methods may have different mechanisms; the current view in this field is that intraspinal cord stimulation may activate the motor cistern and the inherent neural network in the spinal cord to complete coordinated limb movement [87]. The epidural electrical stimulation may increase the baseline excitability of the spinal cord, so as to keep the nerve triggering movement intact after SCI $[41,88]$.

\section{Challenges and Prospects}

Spinal cord electrical stimulation brings new treatment and hopes to patients with SCI, which is very commendable. With the improvement of technology, new stimulators, electrodes, and other devices will be created, and new stimulation strategies will also be proposed [55]. This will further promote the development of electrical stimulation technology and bring good news to patients. At present, although the results of spinal electrical stimulation are expected to play an important role in enhancing motor recovery, the potential for long-term and continuous improvement caused by this technique is likely to require further improvement, such as the biocompatibility of implants [89], noninvasive effectiveness [78, 79]. In addition, a combination of treatments, such as exoskeletons [90, 91], may be required, as well as medication [92], motor training $[58,93]$.

4.1. Challenge. The current spinal cord electrical stimulation technology needs to be further explored: first of all, the motor function repair of patients has not formed a complete circuit. The patient passively receives the stimulation signal or instruction to make the corresponding action, and it is difficult to receive the feedback signal of the stimulated muscle. Although Urbin et al. [94] try to collect the EMG of the target muscle and the foot ground-reaction forces (GRF) signals implanted in the body to build the somatosensory afferent pathway, there is still a long way to go before the recovery of sensory function. In addition, most of the existing motor function reconstruction systems are carried out in the laboratory environment, although some environments approximately simulate the reality. However, experiments conducted in a laboratory environment do not take into account all the availability factors that weaken the functional reconstruction system, including artificial factors, nonbrain effects, and the mental state of the user. Therefore, it is meaningful to add mental and psychological assessment options in future research plans, and a professional training team for the use of the functional reconstruction system should be prepared to make patients quickly and skillfully 
operate the system and put it into practice as soon as possible. Finally, for the realization of motor function, all kinds of rehabilitation methods need an appropriate control strategy [83, 95-97]. At present, human action recognition is not accurate in dynamic situations. Using different algorithm recognition signals to recognize human activities and motion parameters accurately to guide or remotely guide electrical stimulation is a challenge. In the later development process, breakthroughs in signal processing will be an important development direction for electrical stimulation. It will be a long-standing challenge to be able to process stimulus signals efficiently and accurately, and to develop stable and efficient stimulus algorithms. In-depth discussion of the contraction mechanism and internal relationship of each muscle in the muscle group after electrical stimulation is indispensable for patients to achieve motor function. The related research on the mechanism of electrical stimulation should be more detailed and rich, which will be conducive to the development of motor function rehabilitation technology of electrical stimulation.

\subsection{Future Direction}

4.2.1. Electrical Stimulation Technology Based on BCI. Spinal cord electrical stimulation technology based on braincomputer interface will be an important development direction in the future, and the collected EEG signals can be used as control signals to guide stimulation strategies. A research team has applied the collected EEG signals to spinal cord electrical stimulation and made a breakthrough in the treatment of paralyzed patients. As an example, researcher Millan and others collected EEG signals from patients with upper limb paralysis caused by stroke and decoded motor consciousness signals. The research team combined motor consciousness signals based on BCI with spinal cord electrical stimulation to induce significant recovery of upper limb motor function, and the effect was still significant in 6 to 12 months after treatment [98].

This shows that this treatment is effective and persistent, but it is worth noting that the design of brain signal detection and control signal is difficult. This also opens up new doors and challenges for the research direction of spinal cord electrical stimulation technology, such as the detection of EEG signals [99], new control method [97], and inflammatory reaction of intrusive electrode $[100,101]$. In addition, spinal cord electrical stimulation based on BCI requires patients to have good enough motor imagination to generate motor electrical signals; otherwise, it is a difficult problem to control spinal cord electrical stimulation [102-104]. The motor function recovery of FES technology based on BCI has achieved some results, but the curative effect and repair mechanism are not completely clear [98, 105, 106]. This requires further research by researchers, and it may be a good method to establish a good computational model to explore the signal loop $[51,107]$.

4.2.2. Electrical Stimulation and Drug Therapy. In some cases, these pharmacological treatments can enhance the effects of exercise training and epidural stimulation [108].
This combination intervention may target the internal environment of the injured spinal cord to further increase its excitability and enhance the effectiveness of therapeutic electrical stimulation. It was found that chondroitinase gene therapy could significantly enhance the upper limb function, improve the forelimb performance and grip, increase the spinal information transmission, and reduce the pathology of the injured spine after spinal cord contusion in rats [109]. Chondroitinase transmitted by canine mucosal olfactory ensheathing cells combined with rehabilitation can enhance the recovery after SCI [110]. In addition, stem cell transplantation has always been a hot topic in the treatment of SCI and has an early positive effect [111]. Electrical stimulation has a positive effect on stem cell transplantation, and stem cell and neural progenitor cell therapy can also improve hand stretching performance and hand function [112]. Based on these findings, it may be possible to use electrical stimulation to direct stem cells to damaged parts of the body, becoming an important treatment.

4.2.3. Development of Neuroprosthesis. Lagging science and technology and production capacity hinder the development of electrical stimulation system nerve prosthesis and cannot achieve the desired goal, but with the development of technology, there may be a big breakthrough. The composition or auxiliary devices of some electrical stimulation systems will be improved, such as electrodes for transmitting stimulus signals [113], stimulators for generating stimulus pulses [114], sensors for transmitting control source signals [25], and exoskeletons for sports training [115].

In addition, feedback control based on neural prosthesis may promote the progress of electrical stimulation technology. Many researchers use the collected needle electrode EMG for the detection and diagnosis of SCI related diseases, including muscle activation evaluation [116], improved EMG control $[117,118]$, evaluation of motor neuron loss [119], muscle fatigue detection [120], prosthetic EMG control [121], and other fields. The acquisition of surface EMG is closely related to the placement of electrodes, electrode materials, and the number of channels [122-125]. It can be used as a reference for the control of electrical stimulation signal and the evaluation of rehabilitation effect in exercise rehabilitation.

\section{Summary}

In summary, spinal cord injury brings tremendous physical and psychological pressure to patients, causing inconvenience and even loss of life. Researchers have made great efforts to improve the lives of patients with spinal cord injury in their respective fields. This article first introduces the different causes of spinal cord injury and various existing treatment methods and briefly introduces the current understanding of its origin and mechanism of action. Most importantly, this article provides a detailed review of the treatment methods of spinal cord electrical stimulation. Several different spinal cord electrical stimulation methods and corresponding electrical stimulation systems were 
discussed, respectively, and the stimulation effects were analyzed. Finally, this article analyzes the challenges and future directions of the spinal cord electrical stimulation system and gives possible potential research programs. Whether it is advanced stimulation equipment or sophisticated stimulation strategy, spinal cord electrical stimulation technology provides practical help for people with mobility difficulties. This technology helps patients achieve things that were impossible before and even participate in daily life, greatly reducing the burden of life and improving self-confidence. Looking to the future, in order to solve the multifaceted effects of SCI and restore the complete function, a combination of multiple treatments and long-term treatment and training may be needed.

The latest treatment method combining cell transplantation and electrical stimulation has brought new treatment improvements and has made progress in animal models [126]. The pathophysiological mechanism of spinal cord injury is complicated. So far, the mechanism and process are not fully understood [127]. It is worth noting that comprehensive treatments such as surgical biomaterials, stem cell transplantation, drug therapy, and rehabilitation exercises have been proven effective. And the functional remodeling of neural circuits relies heavily on rehabilitation exercises, such as electrical stimulation, physical training, and brain-computer interfaces. In future research, we should pay attention to the individual differences of patients. For patients with incomplete injuries or no ruptures, more attention may be paid to physical rehabilitation training, and electrical stimulation systems are used for auxiliary treatment. For patients with large-scale fracture injuries, surgery or bioprosthetic transplantation may be required to help establish new neural circuits, maximize the effect of rehabilitation, and ultimately promote the research of spinal cord injury to have greater breakthroughs in treatment and rehabilitation and more fields.

\section{Conflicts of Interest}

The authors declare that they have no conflicts of interest.

\section{Acknowledgments}

This research was funded by a grant (No. 2019M660392) from China Postdoctoral Science Foundation and the Open Research Project of the State Key Laboratory of Media Convergence and Communication, Communication University of China (No. SKLMCC2020KF002).

\section{References}

[1] F. S. Chang, Q. Zhang, M. Sun et al., "Epidemiological study of spinal cord injury individuals from halfway houses in Shanghai, China," Journal of Spinal Cord Medicine, vol. 41, no. 4, pp. 450-458, 2017.

[2] H. Chikuda, J. Ohya, H. Horiguchi et al., "Ischemic stroke after cervical spine injury: analysis of 11,005 patients using the Japanese diagnosis procedure combination database," The Spine Journal, vol. 14, no. 10, pp. 2275-2280, 2014.
[3] A. E. Smith, I. R. Molton, and M. P. Jensen, "Self-reported incidence and age of onset of chronic comorbid medical conditions in adults aging with long-term physical disability," Disability and Health Journal, vol. 9, no. 3, pp. 533-538, 2016.

[4] J. T. Street, V. K. Noonan, A. Cheung, C. G. Fisher, and M. F. Dvorak, "Incidence of acute care adverse events and long-term health-related quality of life in patients with TSCI," The Spine Journal, vol. 15, no. 5, pp. 923-932, 2015.

[5] H. Wang, X. Liu, Y. Zhao et al., "Incidence and pattern of traumatic spinal fractures and associated spinal cord injury resulting from motor vehicle collisions in China over 11 years: an observational study," Medicine, vol. 95, no. 43, pp. 1-5, 2016.

[6] National Spinal Cord Injury Statistical Center, "Spinal cord injury (SCI) facts and figures at a glance," The Journal of the American Paraplegia Society, vol. 39, no. 2, pp. 243-244, 2016.

[7] J. R. Wilson, C. D. Witiw, J. Badhiwala, B. K. Kwon, M. G. Fehlings, and J. S. Harrop, "Early surgery for traumatic spinal cord injury: where are we now?" Global Spine Journal, vol. 10, no. 1, pp. 84S-91S, 2020.

[8] E. Hayta and H. Elden, "Acute spinal cord injury: a review of pathophysiology and potential of non-steroidal anti-inflammatory drugs for pharmacological intervention," Journal of Chemical Neuroanatomy, vol. 87, pp. 25-31, 2018.

[9] M. Franz, L. Richner, M. Wirz et al., "Physical therapy is targeted and adjusted over time for the rehabilitation of locomotor function in acute spinal cord injury interventions in physical and sports therapy," Spinal Cord, vol. 56, no. 2, pp. 158-167, 2018.

[10] J. H. Badhiwala, J. R. Wilson, C. D. Witiw et al., "The influence of timing of surgical decompression for acute spinal cord injury: a pooled analysis of individual patient data," The Lancet Neurology, vol. 20, no. 2, pp. 117-126, 2021.

[11] S. Silvestro, P. Bramanti, O. Trubiani, and E. Mazzon, "Stem cells therapy for spinal cord injury: an overview of clinical trials," International Journal of Molecular Sciences, vol. 21, no. 2, 2020.

[12] B. Yang, F. Zhang, F. Cheng et al., "Strategies and prospects of effective neural circuits reconstruction after spinal cord injury," Cell Death \& Disease, vol. 11, no. 6, p. 439, 2020.

[13] G. David, S. Mohammadi, A. R. Martin et al., "Traumatic and nontraumatic spinal cord injury: pathological insights from neuroimaging," Nature Reviews Neurology, vol. 15, no. 12, pp. 718-731, 2019.

[14] N. D. James, S. B. Mcmahon, E. C. Field-Fote, and E. J. Bradbury, "Neuromodulation in the restoration of function after spinal cord injury," The Lancet Neurology, vol. 17, no. 10, pp. 905-917, 2018.

[15] C. H. Ho, R. J. Triolo, A. L. Elias et al., "Functional electrical stimulation and spinal cord injury," Physical Medicine and Rehabilitation Clinics of North America, vol. 25, no. 3, pp. 631-654, 2014.

[16] E. F. Hodkin, Y. Lei, J. Humby et al., “Automated FES for upper limb rehabilitation following stroke and spinal cord injury," IEEE Transactions on Neural Systems and Rehabilitation Engineering, vol. 26, no. 5, pp. 1067-1074, 2018.

[17] N. S. Makowski, L. M. Lombardo, K. M. Foglyano et al., "Walking after incomplete spinal cord injury with an implanted neuromuscular electrical stimulation system and a hinged knee replacement: a single-subject study," Spinal Cord Series and Cases, vol. 6, no. 1, p. 86, 2020.

[18] C. A. Angeli, M. Boakye, R. A. Morton et al., "Recovery of over-ground walking after chronic motor complete spinal 
cord injury," New England Journal of Medicine, vol. 379, no. 13, pp. 1244-1250, 2018.

[19] Y.-T. Zhang, H. Jin, J.-H. Wang et al., “Tail nerve electrical stimulation and electro-acupuncture can protect spinal motor neurons and alleviate muscle atrophy after spinal cord transection in rats," Neural Plasticity, vol. 2017, Article ID 7351238, 11 pages, 2017.

[20] C. Daia, A. M. Bumbea, C. D. Badiu, C. Ciobotaru, and G. Onose, "Interferential electrical stimulation for improved bladder management following spinal cord injury," Biomedical Reports, vol. 11, no. 3, pp. 115-122, 2019.

[21] G. Buzsáki, C. A. Anastassiou, and C. Koch, "The origin of extracellular fields and currents-EEG, ECoG, LFP and spikes," Nature Reviews Neuroscience, vol. 13, no. 6, pp. 407-420, 2012.

[22] C. Moritz, "A giant step for spinal cord injury research," Nature Neuroscience, vol. 21, no. 12, pp. 1645-1646, 2018.

[23] M. R. Popovic, T. Keller, I. P. I. Papas, V. Dietz, and M. Morari, "Surface-stimulation technology for grasping and walking neuroprostheses," IEEE Engineering in Medicine and Biology Magazine, vol. 20, no. 1, pp. 82-93, 2001.

[24] C. Wiesener and T. Schauer, "The cybathlon RehaBike: inertial-sensor-driven functional electrical stimulation cycling by team hasomed," IEEE Robotics and Automation Magazine, vol. 24, no. 4, pp. 49-57, 2017.

[25] C. Wiesener, T. Seel, J. Axelgaard, R. Horton, A. Niedeggen, and T. Schauer, "An inertial sensor-based trigger algorithm for functional electrical stimulation-assisted swimming in paraplegics," IFAC-PapersOnLine, vol. 51, no. 34, pp. 278-283, 2019.

[26] T. Schauer, "Sensing motion and muscle activity for feedback control of functional electrical stimulation: ten years of experience in Berlin," Annual Reviews in Control, vol. 44, pp. 355-374, 2017.

[27] L. Bi, A. G. Feleke, and C. Guan, "A review on EMG-based motor intention prediction of continuous human upper limb motion for human-robot collaboration," Biomedical Signal Processing and Control, vol. 51, pp. 113-127, 2019.

[28] R. E. Singh, K. Iqbal, G. White, and T. E. Hutchinson, "A systematic review on muscle synergies: from building blocks of motor behavior to a neurorehabilitation tool," Applied Bionics and Biomechanics, vol. 2018, Article ID 3615368, 15 pages, 2018.

[29] G. P. Braz, M. Russold, and G. M. Davis, "Functional electrical stimulation control of standing and stepping after spinal cord injury: a review of technical characteristics," Neuromodulation: Technology at the Neural Interface, vol. 12, no. 3, pp. 180-190, 2009.

[30] A. R. Kralj and T. Bajd, Functional Electrical Stimulation: Standing and Walking after Spinal Cord Injury, CRC Press, Boca Raton, FL, USA, 1989.

[31] A. H. Vette, K. Masani, J.-Y. Kim, and M. R. Popovic, "Closed-loop control of functional electrical stimulationassisted arm-free standing in individuals with spinal cord injury: a feasibility study," Neuromodulation: Technology at the Neural Interface, vol. 12, no. 1, pp. 22-32, 2009.

[32] C. L. Lynch, M. R. Popovic, and R. Engineering, "A comparison of closed-loop control algorithms for regulating electrically stimulated knee movements in individuals with spinal cord injury," IEEE Transactions on Neural Systems and Rehabilitation Engineering, vol. 20, no. 4, pp. 539-548, 2012.

[33] Y. Hu, H. Su, J. Fu, H. R. Karimi, G. Ferrigno, and E. D. Momi, "Nonlinear model predictive control for mobile medical robot using neural optimization," IEEE Transactions on Industrial Electronics, vol. 68, no. 12, pp. 12636-12645, 2020.

[34] O. Devinsky, "Electrical and magnetic stimulation of the central nervous system. Historical overview," Advances in Neurology, vol. 63, pp. 1-16, 1993.

[35] C. N. Shealy, J. T. Mortimer, and N. R. Hagfors, "Dorsal column electroanalgesia," Journal of Neurosurgery, vol. 32, no. 5 , pp. $560-564,1970$.

[36] C. N. Shealy, J. T. Mortimer, and J. B. Reswick, "Electrical inhibition of pain by stimulation of the dorsal columns," Anesthesia \& Analgesia, vol. 46, no. 4, pp. 489-491, 1967.

[37] N. Donaldson, T. Perkins, R. Fitzwater, D. E. Wood, and F. Middleton, "FES cycling may promote recovery of leg function after incomplete spinal cord injury," Spinal Cord, vol. 38 , no. 11 , pp. $680-682,2000$.

[38] A. S. Gorgey, D. R. Dolbow, J. D. Dolbow, R. K. Khalil, and D. R. Gater, "The effects of electrical stimulation on body composition and metabolic profile after spinal cord injuryPart II," The Journal of Spinal Cord Medicine, vol. 38, no. 1, pp. 23-37, 2015.

[39] A. Sivaramakrishnan, J. M. Solomon, and N. Manikandan, "Comparison of transcutaneous electrical nerve stimulation (TENS) and functional electrical stimulation (FES) for spasticity in spinal cord injury-a pilot randomized cross-over trial," The Journal of Spinal Cord Medicine, vol. 41, no. 4, pp. 397-406, 2018.

[40] A. N. Sharpe and A. Jackson, "Upper-limb muscle responses to epidural, subdural and intraspinal stimulation of the cervical spinal cord," Journal of Neural Engineering, vol. 11, no. 1, Article ID 016005, 2014.

[41] V. R. Edgerton, G. Courtine, Y. P. Gerasimenko et al., "Training locomotor networks," Brain Research Reviews, vol. 57, no. 1, pp. 241-254, 2008 .

[42] C. H. Tator, K. Minassian, and V. K. Mushahwar, "Chapter 18-spinal cord stimulation: therapeutic benefits and movement generation after spinal cord injury," in Handbook of Clinical Neurology, J. Verhaagen and J. W. Mcdonald, Eds., Elsevier, Amsterdam, Netherlands, pp. 283-296, 2012.

[43] S. Grillner, "Biological pattern generation: the cellular and computational logic of networks in motion," Neuron, vol. 52, no. 5, pp. 751-766, 2006.

[44] L. R. Hochberg, D. Bacher, B. Jarosiewicz et al., "Reach and grasp by people with tetraplegia using a neurally controlled robotic arm," Nature, vol. 485, no. 7398, pp. 372-375, 2012.

[45] N. Wenger, E. M. Moraud, J. Gandar et al., "Spatiotemporal neuromodulation therapies engaging muscle synergies improve motor control after spinal cord injury," Nature Medicine, vol. 22, no. 2, pp. 138-145, 2016.

[46] N. Wenger, E. M. Moraud, S. Raspopovic et al., "Closed-loop neuromodulation of spinal sensorimotor circuits controls refined locomotion after complete spinal cord injury," Science Translational Medicine, vol. 6, no. 255, 2014.

[47] E. M. Moraud, M. Capogrosso, E. Formento et al., "Mechanisms underlying the neuromodulation of spinal circuits for correcting gait and balance deficits after spinal cord injury," Neuron, vol. 89, no. 4, pp. 814-828, 2016.

[48] P. Gad, J. Choe, P. Shah et al., "Sub-threshold spinal cord stimulation facilitates spontaneous motor activity in spinal rats," Journal of NeuroEngineering and Rehabilitation, vol. 10, 2013.

[49] P. Gad, J. Choe, P. Shah et al., "Sub-threshold spinal cord stimulation facilitates spontaneous motor activity in spinal rats," Journal of NeuroEngineering and Rehabilitation, vol. 10, 2013. 
[50] M. Alam, G. Garcia-Alias, B. Jin et al., "Electrical neuromodulation of the cervical spinal cord facilitates forelimb skilled function recovery in spinal cord injured rats," Experimental Neurology, vol. 291, pp. 141-150, 2017.

[51] M. Capogrosso, N. Wenger, S. Raspopovic et al., "A computational model for epidural electrical stimulation of spinal sensorimotor circuits," Journal of Neuroscience, vol. 33, no. 49, pp. 19326-19340, 2013.

[52] E. Formento, K. Minassian, F. Wagner et al., "Electrical spinal cord stimulation must preserve proprioception to enable locomotion in humans with spinal cord injury," Nature Neuroscience, vol. 21, no. 12, pp. 1728-1741, 2018.

[53] L. Friedli, E. S. Rosenzweig, and Q. Barraud, "Pronounced species divergence in corticospinal tract reorganization and functional recovery after lateralized spinal cord injury favors primates," Science Translational Medicine, vol. 7, no. 302, 2015.

[54] M. Capogrosso, T. Milekovic, D. Borton et al., "A brain-spine interface alleviating gait deficits after spinal cord injury in primates," Nature, vol. 539, no. 7628, pp. 284-288, 2016.

[55] N. Greiner, B. Barra, G. Schiavone et al., "Recruitment of upper-limb motoneurons with epidural electrical stimulation of the cervical spinal cord," Nature Communications, vol. 12, no. 1, p. 435, 2021.

[56] S. Mesbah, T. Ball, C. Angeli et al., "Predictors of volitional motor recovery with epidural stimulation in individuals with chronic spinal cord injury," Brain, vol. 144, no. 2, pp. 420-433, 2021.

[57] B. Barra, C. Roux, M. Kaeser et al., "Selective recruitment of arm motoneurons in nonhuman primates using epidural electrical stimulation of the cervical spinal cord," in Proceedings of the Annual International Conference of the IEEE Engineering in Medicine and Biology Society, pp. 1424-1427, Honolulu, HI, USA, 2018.

[58] F. B. Wagner, J.-B. Mignardot, C. G. Le Goff-Mignardot et al., "Targeted neurotechnology restores walking in humans with spinal cord injury," Nature, vol. 563, no. 7729, pp. 65-71, 2018.

[59] G. Courtine and M. V. Sofroniew, "Spinal cord repair: advances in biology and technology," Nature Medicine, vol. 25, no. 6, pp. 898-908, 2019.

[60] J. D. Turtle, M. K. Henwood, M. M. Strain, Y.-J. Huang, R. C. Miranda, and J. W. Grau, "Engaging pain fibers after a spinal cord injury fosters hemorrhage and expands the area of secondary injury," Experimental Neurology, vol. 311, pp. 115-124, 2019.

[61] A. N. Herrity, C. S. Williams, C. A. Angeli, and S. J. Harkemaet, "Lumbosacral spinal cord epidural stimulation improves voiding function after human spinal cord injury," Scientific Reports, vol. 8, 2018.

[62] M. Rath, A. H. Vette, S. Ramasubramaniam et al., "Trunk stability enabled by noninvasive spinal electrical stimulation after spinal cord injury," Journal of Neurotrauma, vol. 35, no. 21, pp. 2540-2553, 2018.

[63] G. Taccola, D. Sayenko, P. Gad, Y. Gerasimenko, and V. R. Edgerton, "And yet it moves: recovery of volitional control after spinal cord injury," Progress in Neurobiology, vol. 160, pp. 64-81, 2018.

[64] S. Harkema, Y. Gerasimenko, J. Hodes et al., "Effect of epidural stimulation of the lumbosacral spinal cord on voluntary movement, standing, and assisted stepping after motor complete paraplegia: a case study," The Lancet, vol. 377, no. 9781, pp. 1938-1947, 2011.
[65] D. Darrow, D. Balser, T. I. Netoff et al., "Epidural spinal cord stimulation facilitates immediate restoration of dormant motor and autonomic supraspinal pathways after chronic neurologically complete spinal cord injury," Journal of Neurotrauma, vol. 36, no. 15, pp. 2325-2336, 2019.

[66] M. Possover, "Ten-year experience with continuous lowfrequency pelvic somatic nerves stimulation for recovery of voluntary walking in people with chronic spinal cord injury: a prospective case series of 29 consecutive patients," Archives of Physical Medicine and Rehabilitation, vol. 102, no. 1, pp. 50-57, 2021.

[67] E. Rejc, C. A. Angeli, N. Bryant, and S. J. Harkema, "Effects of stand and step training with epidural stimulation on motor function for standing in chronic complete paraplegics," Journal of Neurotrauma, vol. 34, no. 9, pp. 1787-1802, 2017.

[68] S. Mangold, T. Keller, A. Curt, and V. Dietz, "Transcutaneous functional electrical stimulation for grasping in subjects with cervical spinal cord injury," Spinal Cord, vol. 43, no. 1, pp. 1-13, 2005.

[69] F. Inanici, S. Samejima, P. Gad, V. R. Edgerton, C. P. Hofstetter, and C. T. Moritz, "Transcutaneous electrical spinal stimulation promotes long-term recovery of upper extremity function in chronic tetraplegia," IEEE Transactions on Neural Systems and Rehabilitation Engineering, vol. 26, no. 6, pp. 1272-1278, 2018.

[70] K. Minassian, I. Persy, F. Rattay, M. R. Dimitrijevic, C. Hofer, and H. Kern, "Posterior root-muscle reflexes elicited by transcutaneous stimulation of the human lumbosacral cord," Muscle \& Nerve, vol. 35, no. 3, pp. 327-336, 2007.

[71] P. K. Bedi and N. Arumugam, "Tapping the neural circuitry: surface spinal stimulation in spinal cord injury: a case report," Journal of Exercise Science \& Physiotherapy, vol. 12, no. 1, pp. 69-75, 2016.

[72] D. G. Sayenko, M. Rath, A. R. Ferguson et al., "Self-Assisted standing enabled by non-invasive spinal stimulation after spinal cord injury," Journal of Neurotrauma, vol. 36, no. 9, pp. 1435-1450, 2018.

[73] P. Gad, Y. Gerasimenko, S. Zdunowski et al., "Weight bearing over-ground stepping in an exoskeleton with noninvasive spinal cord neuromodulation after motor complete paraplegia," Frontiers in Neuroscience, vol. 11, no. 333, p. 333, 2017.

[74] Y. P. Gerasimenko, D. C. Lu, M. Modaber et al., "Noninvasive reactivation of motor descending control after paralysis," Journal of Neurotrauma, vol. 32, no. 24, pp. 1968-1980, 2015.

[75] K. Minassian, U. S. Hofstoetter, S. M. Danner et al., "Spinal rhythm generation by step-induced feedback and transcutaneous posterior root stimulation in complete spinal cordinjured individuals," Neurorehabilitation and Neural Repair, vol. 30, no. 3, pp. 233-243, 2015.

[76] F. Inanici, L. N. Brighton, S. Samejima, C. P. Hofstetter, and C. T. Moritz, "Transcutaneous spinal cord stimulation restores hand and arm function after spinal cord injury," IEEE Transactions on Neural Systems and Rehabilitation Engineering, vol. 29, pp. 310-319, 2021.

[77] S. I. Bîrlea, P. P. Breen, G. J. Corley, N. M. Bîrlea, F. Quondamatteo, and G. ÓLaighin, "Changes in the electrical properties of the electrode-skin-underlying tissue composite during a week-long programme of neuromuscular electrical stimulation," Physiological Measurement, vol. 35, no. 2, pp. 231-252, 2014.

[78] J. L. Lujan and P. E. Crago, "Automated optimal coordination of multiple-DOF neuromuscular actions in 
feedforward neuroprostheses," IEEE Transactions on Biomedical Engineering, vol. 56, no. 1, pp. 179-187, 2009.

[79] D. M. Niddam, T. Graven-Nielsen, L. Arendt-Nielsen, and A. C. N. Chen, "Non-painful and painful surface and intramuscular electrical stimulation at the thenar and hypothenar sites: differential cerebral dynamics of early to late latency SEPs," Brain Topography, vol. 13, no. 4, pp. 283-292, 2001.

[80] A. Megía García, D. Serrano-Muñoz, J. Taylor, J. AvendañoCoy, and J. Gómez-Soriano, "Transcutaneous spinal cord stimulation and motor rehabilitation in spinal cord injury: a systematic review," Neurorehabilitation and Neural Repair, vol. 34, no. 1, pp. 3-12, 2019.

[81] C. Tao, X. Shen, L. Ma et al., "Comparative study of intraspinal microstimulation and epidural spinal cord stimulation," in Proceedings of the 2019 41st Annual International Conference of the IEEE Engineering in Medicine and Biology Society (EMBC), pp. 3795-3798, Berlin, Germany, 2019.

[82] B. J. Holinski, K. A. Mazurek, D. G. Everaert et al., "Intraspinal microstimulation produces over-ground walking in anesthetized cats," Journal of Neural Engineering, vol. 13, no. 5, Article ID 056016, 2016.

[83] A. N. Dalrymple, D. G. Everaert, D. S. Hu, and V. K. Mushahwar, "A speed-adaptive intraspinal microstimulation controller to restore weight-bearing stepping in a spinal cord hemisection model," Journal of Neural Engineering, vol. 15, no. 5, p. 20, 2018.

[84] M. R. Kasten, M. D. Sunshine, E. S. Secrist, P. J. Horner, and C. T. Moritz, "Therapeutic intraspinal microstimulation improves forelimb function after cervical contusion injury," Journal of Neural Engineering, vol. 10, no. 4, 2013.

[85] J. G. Mcpherson, R. R. Miller, and S. I. Perlmutter, "Targeted, activity-dependent spinal stimulation produces long-lasting motor recovery in chronic cervical spinal cord injury," Proceedings of the National Academy of Sciences, vol. 112, no. 39, pp. 12193-12198, 2015.

[86] S. E. Mondello, M. R. Kasten, P. J. Horner, and C. T. Moritz, "Therapeutic intraspinal stimulation to generate activity and promote long-term recovery," Frontiers in Neuroscience, vol. 8, 2014.

[87] C. H. Tator, K. Minassian, and V. K. Mushahwar, "Spinal cord stimulation," Handbook of Clinical Neurology, vol. 109, pp. 283-296, 2012.

[88] S. J. Harkema, "Plasticity of interneuronal networks of the functionally isolated human spinal cord," Brain Research Reviews, vol. 57, no. 1, pp. 255-264, 2008.

[89] D. N. Heo, H.-J. Kim, Y. J. Lee et al., "Flexible and highly biocompatible nanofiber-based electrodes for neural surface interfacing," ACS Nano, vol. 11, no. 3, pp. 2961-2971, 2017.

[90] E. Y. Shapkova, E. V. Pismennaya, D. V. Emelyannikov, and Y. Ivanenko, "Exoskeleton walk training in paralyzed individuals benefits from transcutaneous lumbar cord tonic," Electrical Stimulation, vol. 14, no. 416, 2020.

[91] W. Guan, L. Zhou, and Y. Cao, "Joint motion control for lower limb rehabilitation based on iterative learning control (ILC) algorithm," Complexity, vol. 2021, Article ID 6651495, 9 pages, 2021.

[92] R. Van Den Brand, J. Heutschi, Q. Barraud et al., "Restoring voluntary control of locomotion after paralyzing spinal cord injury," Science, vol. 336, no. 6085, pp. 1182-1185, 2012.

[93] W. Cao, H. Yu, X. Wu, S. Li, Q. Meng, and C. Chen, "Development and evaluation of a rehabilitation wheelchair with multiposture transformation and smart control," Complexity, vol. 2021, Article ID 6628802, 14 pages, 2021.
[94] M. A. Urbin, M. Liu, E. C. Bottorff, R. A. Gaunt, L. E. Fisher, and D. J. Weber, "Hindlimb motor responses evoked by microstimulation of the lumbar dorsal root ganglia during quiet standing," Journal of Neural Engineering, vol. 17, no. 1, Article ID 016019, 2019.

[95] S. Shahdoost, S. B. Frost, D. J. Guggenmos et al., "A brainspinal interface (BSI) system-on-chip (SoC) for closed-loop cortically-controlled intraspinal microstimulation," Analog Integrated Circuits and Signal Processing, vol. 95, no. 1, pp. 1-16, 2018.

[96] X.-y. Shen, W. Du, W. Huang, and Y. Chen, "Rebuilding motor function of the spinal cord based on functional electrical stimulation," Neural Regeneration Research, vol. 11, no. 8, pp. 1327-1332, 2016.

[97] C. Vidaurre, C. Klauer, T. Schauer, A. Ramos-Murguialday, and K.-R. Müller, "EEG-based BCI for the linear control of an upper-limb neuroprosthesis," Medical Engineering \& Physics, vol. 38, no. 11, pp. 1195-1204, 2016.

[98] A. Biasiucci, R. Leeb, I. Iturrate et al., "Brain-actuated functional electrical stimulation elicits lasting arm motor recovery after stroke," Nature Communications, vol. 9, no. 1, p. 2421, 2018.

[99] M. Uma and S. Prabhu, "A feasibility study of BCI based FES model for differently abled people," IOP Conference Series: Materials Science and Engineering, vol. 402, Article ID 012009, 2018.

[100] A. Prasad, Q.-S. Xue, V. Sankar et al., "Comprehensive characterization and failure modes of tungsten microwire arrays in chronic neural implants," Journal of Neural Engineering, vol. 9, no. 5, Article ID 056015, 2012.

[101] C. Bennett, M. Samikkannu, F. Mohammed, W. D. Dietrich, S. M. Rajguru, and A. Prasad, "Blood brain barrier (BBB)disruption in intracortical silicon microelectrode implants," Biomaterials, vol. 164, pp. 1-10, 2018.

[102] A. Thomschewski, A. Strohlein, and P. B. Langthaler, "Imagine there is no plegia. Mental motor imagery difficulties in patients with traumatic spinal cord injury," Frontiers in Neuroscience, vol. 11, p. 9, 2017.

[103] C. E. Bouton, A. Shaikhouni, N. V. Annetta et al., "Restoring cortical control of functional movement in a human with quadriplegia," Nature, vol. 533, no. 7602, pp. 247-250, 2016.

[104] C. Reynolds, B. A. Osuagwu, and A. Vuckovic, "Influence of motor imagination on cortical activation during functional electrical stimulation," Clinical Neurophysiology, vol. 126, no. 7, pp. 1360-1369, 2015.

[105] U. Chaudhary, N. Birbaumer, and A. Ramos-Murguialday, "Brain-computer interfaces for communication and rehabilitation," Nature Reviews Neurology, vol. 12, no. 9, pp. 513-525, 2016.

[106] S. Luo, H. Xu, Y. Zuo, X. Liu, and A. H. All, "A review of functional electrical stimulation treatment in spinal cord injury," NeuroMolecular Medicine, vol. 22, no. 4, pp. 447-463, 2020.

[107] M. Qian, G. Zhong, X. Yan, H. Wang, and Y. Cui, “A closedloop brain stimulation control system design based on brainmachine interface for epilepsy," Complexity, vol. 2020, Article ID 3136715, 15 pages, 2020 .

[108] G. Taccola, B. H. Salazar, R. Apicella, M. K. Hogan, P. J. Horner, and D. Sayenko, "Selective antagonism of A1 adenosinergic receptors strengthens the neuromodulation of the sensorimotor network during epidural spinal stimulation," Frontiers in Systems Neuroscience, vol. 14, p. 44, 2020.

[109] N. D. James, J. Shea, E. M. Muir, J. Verhaagen, B. L. Schneider, and E. J. Bradbury, "Chondroitinase gene 
therapy improves upper limb function following cervical contusion injury," Experimental Neurology, vol. 271, pp. 131-135, 2015.

[110] J. Prager, D. Ito, D. R. Carwardine et al., "Delivery of chondroitinase by canine mucosal olfactory ensheathing cells alongside rehabilitation enhances recovery after spinal cord injury," Experimental Neurology, vol. 340, Article ID 113660, 2021.

[111] R. M. Grumbles, Y. Liu, C. M. Thomas, P. M. Wood, and C. K. Thomas, "Acute stimulation of transplanted neurons improves motoneuron survival, axon growth, and muscle reinnervation," Journal of Neurotrauma, vol. 30, no. 12, pp. 1062-1069, 2013.

[112] S. M. Schaal, B. M. Kitay, K. S. Cho et al., "Schwann cell transplantation improves reticulospinal axon growth and forelimb strength after severe cervical spinal cord contusion," Cell Transplantation, vol. 16, no. 3, pp. 207-228, 2007.

[113] A. D. Koutsou, J. C. Moreno, A. J. Del Ama, E. Rocon, and J. L. Pons, "Advances in selective activation of muscles for non-invasive motor neuroprostheses," Journal of NeuroEngineering and Rehabilitation, vol. 13, no. 1, p. 56, 2016.

[114] M. Alam, S. Li, R. U. Ahmed et al., "Development of a battery-free ultrasonically powered functional electrical stimulator for movement restoration after paralyzing spinal cord injury," Journal of NeuroEngineering and Rehabilitation, vol. 16, no. 1, p. 36, 2019.

[115] S. Mazzoleni, E. Battini, A. Rustici, and G. Stampacchia, "An integrated gait rehabilitation training based on functional electrical stimulation cycling and overground robotic exoskeleton in complete spinal cord injury patients: preliminary results," in Proceedings of the International Conference on Rehabilitation Robotics (ICORR), pp. 289-293, London, UK, 2017.

[116] W. Kohei and A. Hiroshi, "Validity of surface electromyography for vastus intermedius muscle assessed by needle electromyography," Journal of Neuroscience Methods, vol. 198, no. 2, pp. 332-335, 2011.

[117] E. N. Kamavuako, E. J. Scheme, and K. B. Englehart, "Combined surface and intramuscular EMG for improved real-time myoelectric control performance," Biomedical Signal Processing and Control, vol. 10, pp. 102-107, 2014.

[118] L. Zhang, Z. Li, Y. Hu, C. Smith, E. M. G. Farewik, and R. Wang, "Ankle joint torque estimation using an EMGdriven neuromusculoskeletal model and an artificial neural network model," IEEE Transactions on Automation Science and Engineering, vol. 18, no. 2, pp. 564-573, 2021.

[119] M. Gawel, E. Zalewska, E. Szmidt-Salkowska et al., "Motor Unit Number Index (MUNIX) as a biomarker of motor unit loss in post-polio syndrome versus needle EMG," Journal of Electromyography and Kinesiology, vol. 46, pp. 35-40, 2019.

[120] G. Marco, B. Alberto, and V. Taian, "Surface EMG and muscle fatigue: multi-channel approaches to the study of myoelectric manifestations of muscle fatigue," Physiological Measurement, vol. 38, no. 5, pp. R27-R60, 2017.

[121] O. W. Samuel, H. Zhou, X. Li et al., "Pattern recognition of electromyography signals based on novel time domain features for amputees' limb motion classification," Computers \& Electrical Engineering, vol. 67, pp. 646-655, 2018.

[122] M. Bhadane, J. Liu, W. Z. Rymer, P. Zhou, and S. Li, "Reevaluation of EMG-torque relation in chronic stroke using linear electrode array EMG recordings," Scientific Reports, vol. 6, no. 1, Article ID 28957, 2016.
[123] Y. Liu, L. Tian, M. S. Raj et al., "Intraoperative monitoring of neuromuscular function with soft, skin-mounted wireless devices," Npj Digital Medicine, vol. 1, no. 1, p. 19, 2018.

[124] N. A. Chaya, B. R. Bhavana, S. B. Anoogna, M. Hiranmai, and N. Krupa B, "Real-time replication of arm movements using surface EMG signals," Procedia Computer Science, vol. 154, pp. 186-193, 2019.

[125] A. Botter, M. Beltrandi, G. L. Cerone, M. Gazzoni, and T. M. M. Vieira, "Development and testing of acousticallymatched hydrogel-based electrodes for simultaneous EMGultrasound detection," Medical Engineering \& Physics, vol. 64, pp. 74-79, 2019.

[126] F. O. Fadeev, F. V. Bashirov, V. A. Markosyan et al., "Combination of epidural electrical stimulation with ex vivo triple gene therapy for spinal cord injury: a proof of principle study," Neural regeneration research, vol. 16, no. 3, pp. 550-560, 2021.

[127] B. Yang, F. Zhang, F. Cheng et al., "Strategies and prospects of effective neural circuits reconstruction after spinal cord injury," Cell Death \& Disease, vol. 11, no. 6, pp. 439-514, 2020. 